\title{
An experimental approach to the determination of the gross activity of uranium, plutonium, americium and strontium in human biological samples using solid-state scintillation
}

\author{
Jiři Janda, Jitka Ticha
}

\begin{abstract}
Rapid bioassay methods have been mainly proposed for the sequential measurements of actinides in human blood, bone marrow and urine. The method involves sample treatment using microwave digestion techniques followed by direct measurement of digested products using powder scintillator and alkaline solution as a replacement for traditional liquid scintillation cocktail. The selected group of radionuclides was chosen due to their occurrence in the nuclear fuel cycle, nuclear accident, high radiotoxicity, and the possibility of potential misuses, such as dirty bombs. The work aimed at verifying the connection of microwave digestion using alkaline solution with solid-state scintillation using a powder scintillator YAP:Ce together with an alkaline medium.
\end{abstract}

Keywords: rapid bioassay method; microwave decomposition; solid-state scintillation; YAP:Ce;

\section{Introduction}

Radiation monitoring describes the measurement of radiation dose or contamination, for reasons related to the assessment or control of exposure to radiation or radioactive material, and the interpretation of the results. The monitoring is carried out in response to not only an incident involving the malevolent use of radiation or radioactive material in a public place, but also different radiological and nuclear accidents and may be subdivided into source monitoring, environmental monitoring and individual monitoring [1].

Individual monitoring is monitoring using measurements of quantities of radioactive material in or on the body of the individual, or measurements made by equipment worn by individual workers. It includes the assessment of radiation doses to the individual from the results of measurements. The primary monitoring method is the method that is expected

Manuscript received July 7, 2017; accepted February 20, 2018.

Jiři Janda and Jitka Ticha are with the University of Defence, NBC Defence Institute, Vita Nejedleho, Vyskov, CZ 
to provide the most reliable assessment of internal dose. The measurement is likely to be carried out in a laboratory. For most radionuclides, more rapid measurements [2-6] can be carried out in the field, although these will in general be less accurate. Such measurements are of most use for triage purposes, and are referred to as rapid screening methods.

Samples of urine [6], feces [7], blood [8], nasal swabs [9], saliva can be used. The purpose of the initial screening, with field survey equipment, is to classify people according to their levels of internal contamination, as a guide to decisions on further action [1].

The biochemistry of the multivalent actinides, particularly $\mathrm{Pu}(\mathrm{IV})$, share some metabolic properties with $\mathrm{Fe}(\mathrm{III})$. When present in the blood, both $\mathrm{Pu}(\mathrm{IV})$ and $\mathrm{Np}(\mathrm{IV})$ are quantitatively bound (>90\%) to transferrin (Tf), whereas $\mathrm{U}(\mathrm{VI}), \mathrm{Am}(\mathrm{III})$, and $\mathrm{Np}(\mathrm{V})$ are only weakly bound to Tf [10-13]. While U(VI) is thought to bind to hemoglobin and red blood cells, $\mathrm{Am}(\mathrm{III})$ can associate with albumin, and $\mathrm{Np}(\mathrm{V})$ is believed to complex carbonate ions [10-12].

Once absorbed from the different sites of intake, $\mathrm{Pu}$ circulates in the blood predominantly as $\mathrm{Pu}(\mathrm{IV})$ tightly complexed with plasma proteins or small polycarboxylate ligands such as citrate or lactate [14]. Pu then gets distributed to sites rich in blood sinusoids, such as the liver and the red bone marrow, and deposits in the tissues as an ion complexed by protein metal-binding sites or as insoluble particulates. It has been found associated with hemosiderin (in bone marrow macrophages), ferritin (in liver, spleen, and bone marrow), or as insoluble aggregates encapsulated in the fibrotic material in the lungs [10,14].

Though $\mathrm{U}$ is a common trace element and some intake and accumulation in living organisms is natural, both ?-emitters U-235 and U-238 can induce radiation damage and carcinogenesis, as well as chemical damage in the kidneys and liver [11]. Among the four oxidation states of uranium (III, IV, V, and VI), the uranyl ion $\left(\mathrm{UO}_{2}^{2+}, \mathrm{U}(\mathrm{VI})\right)$ is the most stable form in aqueous solutions and in vivo, and uranyl compounds have therefore be the focus of most pharmacology studies $[11,15]$. In humans, biokinetic models predict the following distribution of uranium, $24 \mathrm{~h}$ after an intake: skeleton $15 \%$, kidneys $17 \%$, other tissues $5 \%$, and urine $63 \%[10,16]$.

For the whole sequence of trivalent actinides, overall initial distribution patterns are similar, with bone and liver being the major deposition sites. The larger animals (dogs and baboons) retained more $\mathrm{Am}^{3+}, \mathrm{Cm}^{3+}, \mathrm{Cf}^{3+}$, and $\mathrm{Es}^{3+}$ in the bulk soft tissues, mainly muscle and pelt, than did the rats and mice. Renal excretion of the trivalent elements was found to be limited, indicating that metal uptake into the target tissues is rapid and that the major fraction of circulating metal is bound to non-filterable protein. In addition, skeletal fraction and renal excretion were found to be somewhat greater for the heavier elements. The partitioning between deposition in bone and liver shifts from predominant liver uptake to bone deposition with the decrease in ionic radius seen along the series $[10,11,17,18]$.

The paper deals with the rapid determination of actinides and fission products, namely uranium, plutonium, americium and strontium/yttrium in human samples such as blood, bone marrow and urine using microwave digestion and solid-state scintillation counting. 
The samples were chosen with respect to the accumulation of actinides during both early and late phase of contamination as was mentioned above. The solid-state scintillation counting using YAP:Ce fine scintillation powder found to be promising substituent to traditional scintillation cocktail [19].

\section{Experimental}

\subsection{Devices and equipment}

The digestion of samples was performed by Multiwave ECO (Anton Paar GmbH) with an inner carrousel consisting of sixteen positions for pressure vessels HVT50 with 20 bar opening pressure. The measurements were carried out using Liquid Scintillation Counter Triathler (Hidex, Finland) with $20 \mathrm{ml}$ PE vials. The "Rn222" program was selected for measurement and subsequently changed to contain following settings: the PLI index was set to one, time of the measurement was set to $300 \mathrm{~s}$, alpha and beta window was set to full width (1-1023 channel), the YGain was 167 and YPos was 48. Proper shaking was performed by shaker IKA KS 130 basic (IKA, USA) and centrifuge MPW-340 (MPW, PL) was used for accelerating of sedimentation.

\subsection{Chemicals}

The scintillation powder YAP:Ce (0-30 $\mu \mathrm{m}$ grain size, CRYTUR, spol. s r.o., CZ) was used as a scintillation media. Radiochemical isotope tracers $\mathrm{U}_{N A T}\left(0.1\right.$ Bq. $\left.\mu 1^{-1}\right), \mathrm{Pu}-239$ (1.1 Bq. $\left.\mu 1^{-1}\right)$, Am-241 (1.67 Bq. $\left.\mu 1^{-1}\right)$ and Sr-90 (0.654 Bq. $\left.\mu 1^{-1}\right)$ were obtained from AEA Technology, UK, QSA Amersham International and CMI (the Czech Metrological Institute). $\mathrm{U}_{N A T}$ tracer was prepared to be self-cleaning, removing its Th-228 daughter using ion exchange resin BIORAD AG 1-X8 (400-800 mesh). The measuring solution contained $0.1 \mathrm{~mol}^{-1} \mathrm{I}^{-1} \mathrm{HNO}_{3}$.

Digestion solution consisted of sodium hydroxide and hydrogen peroxide (Lach-ner, Inc., CZ). Water was obtained from a DEMIWA 5 ROSAT (Watek) water purification system.

The investigated samples blood and bone marrow were obtained from domestic pig due to the close similarity with human biology. Finally, urine samples were collected from humans.

\subsection{Experimental procedures}

The technique used for digestion of samples was as follows. A sample of known mass or volume was transferred to an inner vessel and $50 \mu L$ of a radioactive Am-241 solution of desired activity was added. The entire procedure was repeated for all investigated radionuclides except for $U_{N A T}$, where $200 \mu L$ was added. In case of solids, they were then put into a 
Jiři Janda, Jitka Ticha

hot air oven and slightly dried out. Afterward, all samples were treated with an appropriate mixture of sodium hydroxide and hydrogen peroxide. Vessels were kept in a fume hood until exothermal reaction occurred, and then all vessels were inserted in the Multiwave ECO. The suitable digestion program was chosen for digestion. All programs were adjusted to ensure the highest decomposition and measurement efficiency. After digestion, $2 \mathrm{ml}$ of the decomposed solution were transferred into a scintillation vial containing $0.1 \mathrm{~g}$ of YAP:Ce and $9 \mathrm{ml}$ of $0.5 \mathrm{M} \mathrm{NaOH}$ solution. The set of vials was placed on the shaker; the rate of shaking was set to $700 \mathrm{rpm}$ and left to be shaken for $5 \mathrm{~min}$. Finally, all vials were placed in the centrifuge and spun at $2058 \mathrm{RCF}$ for $5 \mathrm{~min}$. The procedure was adopted according to [19].

After that, the scintillation vial was put in Triathler and measured for $300 \mathrm{~s}$. For each sample type, also the blank sample was created and measured.

Digestion of blood

The $1 \mathrm{ml}$ of blood was transferred into the vessel followed by $3 \mathrm{ml}$ of $\mathrm{H}_{2} \mathrm{O}_{2}$ and $10 \mathrm{ml}$ of $3 \mathrm{M} \mathrm{NaOH}$. The digestion program was following:

\begin{tabular}{|l|l|l|l|}
\hline $\mathrm{T}[\mathrm{C}]$ & Ramp Time $[\mathrm{min}]$ & T of digestion $[\mathrm{min}]$ & Power $[\mathrm{W}]$ \\
\hline 100 & 6 & 10 & 30 \\
\hline 160 & 2 & 10 & 65 \\
\hline 180 & 2 & 12 & 75 \\
\hline 50 & 1 & 10 & 0 \\
\hline
\end{tabular}

Digestion of bone marrow

Two types of bone marrow are recognized, the red one, or hematopoietic is highly vascular and enriched with many blood vessels and capillaries. It gets its red color from the hemoglobin in the erythroid cells. The second one, yellow, or stromal, gets its yellow color from the carotenoids in the fat droplets in the high number of fat cells, produces fat and store adipocytes whose triglycerides can serve as a source for energy. Since there are two completely chemically different types of bone marrow, also the used chemicals differed. In case of red type, the $0.2 \mathrm{~g}$ of bone marrow was transferred into the vessel followed by $3 \mathrm{ml}$ of $\mathrm{H}_{2} \mathrm{O}_{2}$ and $10 \mathrm{ml}$ of $3 \mathrm{M} \mathrm{NaOH}$. In case of yellow type $6 \mathrm{ml}$ of $\mathrm{H}_{2} \mathrm{O}_{2}$ and $6 \mathrm{ml}$ of $3 \mathrm{M}$ $\mathrm{NaOH}$ was used. The digestion program was following:

\begin{tabular}{|l|l|l|l|}
\hline $\mathrm{T}[\mathrm{C}]$ & Ramp Time $[\mathrm{min}]$ & T of digestion $[\mathrm{min}]$ & Power $[\mathrm{W}]$ \\
\hline 100 & 6 & 10 & 30 \\
\hline 150 & 2 & 10 & 65 \\
\hline 170 & 2 & 10 & 75 \\
\hline 50 & 1 & 10 & 0 \\
\hline
\end{tabular}

Digestion of urine 
The $1 \mathrm{ml}$ of human urine was transferred into the vessel. Then $5 \mathrm{ml}$ of $\mathrm{H}_{2} \mathrm{O}_{2}$ and $5 \mathrm{ml}$ of $3 \mathrm{M} \mathrm{NaOH}$ were added. The digestion was realized in the same way as blood.

\section{Results and discussion}

In terms of biological testing to determine the actinide elements in the human body uses samples excreted from the exposed individual. In exposed workers, monitoring internal radiological dose in urine is the preferred method. Since the only small amount of internally deposited americium, plutonium and uranium is excreted, it serves as a background for estimation of the deposited amount of selected radionuclides. Due to the fact, that majority of actinides are bound in blood shortly after the intake, blood seems to be a very promising sample for dose estimation. Another possible biological sample is post-mortem sampling of the bones, due to the good accumulation of radionuclides in the bone marrow. The main challenge of the work was to find proper alkaline based leaching reagent, which is, in connection with microwave digestion system, capable to completely decompose the biological matrix. As one of the suitable solutions, a mixture of sodium hydroxide and hydrogen peroxide fulfilled all criteria; to completely digest and be in alkaline solution. The second condition was necessary due to sorption of radionuclides onto a surface of powder scintillator, in this case of YAP:Ce, under high $\mathrm{pH}$. Using this feature verified in [19], the fine YAP:Ce powder can act in a similar way as a liquid scintillation cocktail with the difference that the radionuclides are bound on the surface of the powder.

Due to the chemical nature of samples, matrix pretreatment was completely omitted and samples were put directly into the vessels. This ability led to a further acceleration of the procedure resulting in time savings. The products of mineralization procedure are shown in Fig. 1.
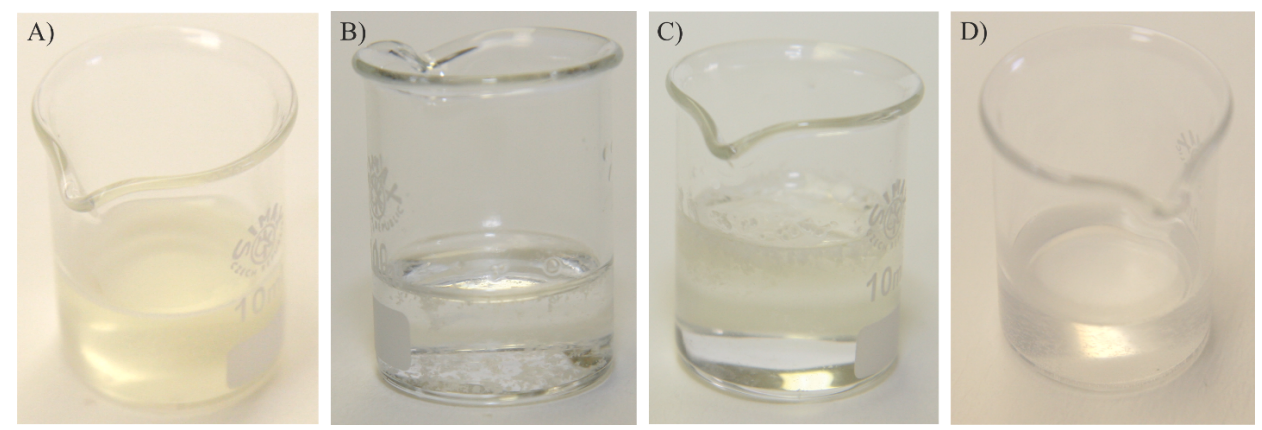

Fig. 1. Digestion products of the selected bioassay samples; A) Blood, B) Red bone marrow, C) Yellow Red bone marrow, D) Urine

In the case of the blood sample, the decomposition was absolute; the color of the solution was slightly yellow, the content was transparent without turbidity. Similarly, even 
Jiři Janda, Jitka Ticha

the better results were observed in the final product of urine digestion. The content was ideal; it was a colorless and transparent solution without any turbidity. The final product of digested bone marrow exhibited mild turbidity. The degree of the turbidity slightly differed from sample to sample, but it was observed, that red type of bone marrow samples exhibited weaker turbidity than the yellow type of bone marrow samples. The results implied that the more fat cells were in the sample, the greater the turbidity of the final solution was observed. Although the presence of the turbidity the resulting solution was colorless and transparent.

Table 1. Detection efficiency of investigated radionuclides in selected decomposed biological samples. The number of analyzed samples is 3 and the standard deviation is $1 \sigma$.

\begin{tabular}{lcccc}
\hline Radionuclides & \multicolumn{4}{c}{ Detection efficiency [\%] } \\
\cline { 2 - 5 } & Blood & $\begin{array}{c}\text { Red bone } \\
\text { marrow }\end{array}$ & $\begin{array}{c}\text { Yellow bone } \\
\text { marrow }\end{array}$ & Urine \\
\hline $\mathrm{Sr}-90$ & $23 \pm 4$ & $45 \pm 3$ & $40 \pm 4$ & $56 \pm 3$ \\
\hline $\mathrm{U}_{N A T}$ & $48 \pm 5$ & $52 \pm 4$ & $55 \pm 3$ & $57 \pm 4$ \\
\hline $\mathrm{Pu}-238$ & $10 \pm 6$ & $26 \pm 5$ & $40 \pm 3$ & $36 \pm 4$ \\
\hline $\mathrm{Am}-241$ & $82 \pm 3$ & $97 \pm 2$ & $98 \pm 3$ & $99 \pm 2$ \\
\hline Background $\left[\mathrm{s}^{-1}\right]$ & 0.7 & 0.7 & 0.7 & 0.6 \\
\hline
\end{tabular}

As can be seen in Tab 1., the obtained results of detection efficiencies for investigated nuclides corresponded with those published in [19]. The highest detection efficiencies were achieved when americium was measured. Samples of bone marrow and urine exhibited almost absolute detection efficiency, while blood samples showed approximately only 82 $\%$. In addition, uranium exhibited steady detection efficiency in all investigated samples, which was $53 \%$ in average. The highest detection efficiency for strontium / yttrium was achieved in a urine sample. Both types of bone marrow exhibited almost similar detection efficiency of about $43 \%$. The lowest detection efficiency was observed when digested blood samples were measured. Contrary to results obtained in [19] the lowest average detection efficiency was achieved when plutonium was applied, especially in connection with blood samples and red bone marrow, where the detection efficiency dropped to $10 \%$ and $26 \%$ respectively.

\section{Conclusion}

A major release of radioactivity to the environment, regardless of whether it was an unfortunate accident or a deliberate act, is always of concern, owing to potential acute and long-term health effects. Evidence from historic events confirms that any major uncontrolled release of radiation should be cause for immediate response and scientific assessment of potential health effects. Such response represents a set of rapid, reliable and practi- 
cal measurement techniques. This paper offers interesting, very experimental and attractive approach how to assess internal contamination in relatively short time after intake or evaluation of post-mortem samples. In spite of the fact that the investigated technique suffers from a number of problems, such as the difficulties during the digestion process, sometimes incomplete decomposition of samples, high selectivity and detection efficiency for trivalent actinides, low for divalent lanthanides, etc., this method of measuring radioactive contamination conceals great potential. Another point of its favor is almost no generation of toxic waste, which, under different circumstances, might be very convenient, because in case of measuring samples containing radionuclides with activities lower than clearance limits, all products arose during the digestion and measurement process can be freely discarded.

\section{References}

[1] T. Rahola, M. Muikku, G, Etherington, A. Hodgson, M. Youngman, C. RojasPalma, K. Meer, A. Liland, A. Jaworska, A. Jerstad, P. Kruse, M. R. Prez, Z. CARR, G. SMAGALA, Guidelines for triage and monitoring of people exposed to radiation after a malevolent act. Downloaded at http://www.irpa12.org.ar/fullpapers/FP3395.pdf.

[2] J. KuWABARA, H. NoguCHI, Development of rapid bioassay method for plutonium, J. Radioanal. Nucl. Chem. 252 (2002), 273-276.

[3] S. L. MAXWELL, Rapid method for determination of plutonium, americium and curium in large soil samples, J. Radioanal. Nucl. Chem. 275 (2008), 395-402.

[4] J. Qiao, X. Hou, P. Roos, M. Miro, Rapid Determination of Plutonium Isotopes in Environmental Samples Using Sequential Injection Extraction Chromatography and Detection by Inductively Coupled Plasma Mass Spectrometry, Anal. Chem. 81 (2009), 8185-8192.

[5] L. SALONEN, A rapid method for monitoring of uranium and radium in drinking water, Sci Total Environ 130-131 (1993), 23-35.

[6] V. N. Epov, K. Benkhedda, R. J. CoRnetT, R. D. Evans, Rapid determination of plutonium in urine using flow injection on-line preconcentration and inductively coupled plasma mass spectrometry, J. Anal. At. Spectrom 20 (2005), 424-430.

[7] A. Gagné, J. Surette, S. Kramer-Tremblay, A bioassay method for americium and curium in feces, J. Radioanal. Nucl. Chem. 295 (2013), 477-482.

[8] Y. Muramatsu, S. Yoshida, T. Ban-Nai, M. AKAshi, Determination of radionuclides in human and environmental samples from the criticality accident in Tokai-mura, Japan, J. Radioanal. Nucl. Chem 262. (2004), 129-134.

[9] D. SAS, P. SLÁDEK, J. JANDA, Measuring alpha and beta activity of filter and swab samples with LSC, J. Radioanal. Nucl. Chem. 286 (2010), 513-517

[10] J. K. Gibson, W. A. DE Jong, Experimental and Theoretical Approaches to Actinide Chemistry, John Wiley \& Sons, New York, 2018.

[11] P. W. Durbin, Actinides in animals and man. In: Chemistry of the Actinide and Transactinide Elements, Springer (2008), 3339-3440. 
[12] D. M. TAYLOR, The bioinorganic chemistry of actinides in blood, J. Alloys. Compd. 271 (1998), 6-10.

[13] A. Jeanson, M. Ferrand, H. Funke, C. Hennig, P. Moisy, P. L. Solari, C. Vidaud, C. DEN AUwER, The role of transferrin in actinide (IV) uptake: Comparison with iron (III), Chem. Eur. J. 16 (2010), 1378-1387.

[14] D. M. TAYLor, Chemical and physical properties of plutonium. In: Uranium, Plutonium, Transplutonic Elements, Springer (1973), 323-347.

[15] E. Ansoborlo, O. Prat, P. Moisy, C. Den Auwer, P. Guilbaud, M. Carriere, B. Gouget, J. Duffield, D. DoizI, T. Vercouter, Actinide speciation in relation to biological processes, Biochimie 88 (2006), 1605-1618.

[16] W. Bair, W. Bloch, W. Dickerson, K. Eckerman, R. Goans, A. Karem, R. Leggett, J. Lipsztein, M. StABin, A. L. Wiley, Management of Persons Contaminated with Radionuclides: Handbook, NCRP (National Council on Radiation Protection and Measurements), Bethesda, MD (USA), 2008.

[17] P. W. DURBin, Metabolism and biological effects of the transplutonium elements. In: Uranium, Plutonium, Transplutonic Elements, Springer (1973), 739-896.

[18] P. W. Durbin, Distribution of the transuranic elements in mammals, Health Phys 8 (1962), 665-671.

[19] J. JANDA, The comparison of scintillation properties of YAP:Ce, YAG:Ce and ZnO:Ga powders as a potential substitution of LSC cocktail, J. Radioanal. Nucl. Chem. 314 (2017), 573582. 